\title{
Incidentally diagnosed renal cancer following investigation for new-onset hyperglycemia
}

\author{
Yukinori Harada*, Yuuta Hara \\ Department of Internal Medicine, Nagano Chuo Hospital, Nagano, Japan
}

Received: April 17, 2016

DOI: $10.5430 /$ crim.v3n3p22
Accepted: June 3, 2016

URL: http://dx.doi.org/10.5430/crim.v3n3p22

\begin{abstract}
Detecting paraneoplastic syndrome is important for the diagnosis of renal cancer. We present an incidentally detected case of renal cancer during the investigation of new-onset hyperglycemia in a 68-year-old woman. The patient presented with palpitations and weight loss; her laboratory findings showed hyperglycemia, anemia, and elevated C-reactive protein and alkaline phosphatase levels. Computed tomography revealed a right renal cancer. Following tumor removal, her glycemic control improved, and insulin therapy, which was needed preoperatively, was not needed anymore. Clinicians should suspect renal cancer in patients with new-onset hyperglycemia occurring simultaneously with interleukin-6-associated paraneoplastic syndrome.
\end{abstract}

Key Words: Hyperglycemia, Paraneoplastic syndrome, Renal cancer

\section{INTRODUCTION}

Detecting paraneoplastic syndromes is important for the diagnosis of renal cancer. It is estimated that $10 \%-40 \%$ of patients with renal cancer develop paraneoplastic syndromes. ${ }^{[1]}$ More importantly, the presence of paraneoplastic syndromes may frequently constitute the initial manifestation of renal cancer. ${ }^{[1]}$ Hyperglycemia has been reported as a constituent symptom of paraneoplastic syndromes, ${ }^{[1]}$ and an association between hyperglycemia and the detection of interleukin-6 in the serum and tumor of patients with renal cancer has been suggested. ${ }^{[2,3]}$ In addition, other features of paraneoplastic syndromes, such as anemia, hepatic dysfunction, and elevation of prostaglandin levels, have also been reported to be associated with the presence of interleukin- 6 in the setting of renal cancer. ${ }^{[1,4,5]}$ However, the association between hyperglycemia and other symptoms of paraneoplastic syndromes in patients with renal cancer as well as the importance of this relationship in the diagnosis of renal cancer remains unknown. Here, we report a case of renal cancer detected incidentally during investigation for the cause of hyperglycemia with anemia and elevation of alkaline phosphatase and C-reactive protein levels in a patient.

\section{Case presentation}

A 68-year-old woman was admitted to our hospital with acute-onset palpitations following an 1-week history of nocturia and $8 \%$ loss in body weight over 2 months. The patient denied any history of excessive thirst, polydipsia, malaise, lower back ache, gross hematuria. She had no significant past medical history and reported that reports of her last medical check-up comprising a complete blood count, blood chemistry, urinalysis, electrocardiogram, and chest radiograph 4 months back, were normal. There was a family history of type 2 diabetes mellitus (patient's mother), but no family history of malignancy. The patient was not on any regular medication, was a non-smoker, and consumed alcohol only

*Correspondence: Yukinori Harada, MD; Email: yuki.gym23@gmail.com; Address: Nishitsuruga 1570, Nagano 380-0814, Japan. 
occasionally. She denied any prior exposure to cadmium, benzene, trichloroethylene, or asbestos.

On physical examination, her height was $146.4 \mathrm{~cm}$, weight $44.0 \mathrm{~kg}$, and body mass index $20.5 \mathrm{~kg} / \mathrm{m}^{2}$. Her general appearance was unremarkable, body temperature was $37.2^{\circ} \mathrm{C}$, blood pressure was $152 / 88 \mathrm{mmHg}$, pulse rate was $152 / \mathrm{min}$, and respiratory rate was normal, with an oxygen saturation of $98 \%$ on room air. Head and neck examination revealed no features of anemia, icterus, or goiter. Examination of the oropharynx showed no aphthae, and her mucous membranes were moist. Cardiovascular examination was normal, and her lungs were clear on auscultation. Abdominal examination was unremarkable with no obvious hepatosplenomegaly or palpable flank mass. She had no peripheral edema. Neurological examination showed normal deep tendon reflexes, and there was no evidence of impairment of her sense of vibration.

Laboratory investigations revealed a microcytic anemia (hemoglobin $11.0 \mathrm{~g} / \mathrm{dl}$, mean corpuscular volume $76.0 \mathrm{fl}$ ), moderately elevated white blood cell and platelet counts $\left(10,730 / \mu 1\right.$ and $61.9 \times 10^{4} / \mu 1$, respectively $)$, hyperglycemia with elevated glycated hemoglobin levels (random blood glucose $353 \mathrm{mg} / \mathrm{dl}$ and hemoglobin A1c 11.7\%), elevated alkaline phosphatase levels (667 IU/L) with normal transaminase levels (aspartate transaminase $25 \mathrm{IU} / \mathrm{L}$, alanine transaminase $32 \mathrm{IU} / \mathrm{L}$ ), moderately low albumin levels with hyperglobulinemia (total protein $7.9 \mathrm{~g} / \mathrm{dl}$, albumin $2.5 \mathrm{~g} / \mathrm{dl}$, Immunoglobulin A $585 \mathrm{mg} / \mathrm{dl}$, Immunoglobulin G 1,941 mg/dl, and Immunoglobulin M $96 \mathrm{mg} / \mathrm{dl}$ ), slightly elevated corrected calcium levels $(10.6 \mathrm{mg} / \mathrm{dl})$, and severely elevated C-reactive protein levels $(17.56 \mathrm{mg} / \mathrm{dl})$. Blood urea nitrogen and serum creatinine levels were normal $(7.1 \mathrm{mg} / \mathrm{dl}$ and 0.33 $\mathrm{mg} / \mathrm{dl}$, respectively). Spot urinalysis showed low specific gravity $(<1.005)$, severe glucosuria $(++++)$, and ketonuria. Hematuria was not obvious (+/-), and there was no evidence of proteinuria. Chest radiograph did not show any abnormality, and an electrocardiogram revealed sinus tachycardia (heart rate 140/min) with no other abnormal findings.

Following admission, a detailed examination focused on glucose metabolism was performed. As she had been treated with insulin injections since admission, her insulin secretion capacity was assessed with blood or urine C-peptide levels. Her anti-glutamic acid decarboxylase antibody test was negative. Although fasting and 2-hour postprandial serum C-peptide levels were close to the lower limits of normal (1.16 and $1.36 \mathrm{ng} / \mathrm{ml}$ respectively), her fasting C-peptide index (fasting $\mathrm{C}$-peptide level divided by fasting serum glucose level $\times 100=0.56)$ and 24-hour urinary C-peptide excretion $(0.2 \mu \mathrm{g} /$ day $)$ were quite low. She was subsequently

Published by Sciedu Press diagnosed with insulin-dependent diabetes mellitus. Several follow-on tests for the evaluation of diabetic complications revealed no micro albuminuria, retinopathy, or neuropathy.

As this patient had presented with an unusual clinical course for a diagnosis of type 2 diabetes, along with the presence of unexplained abnormal laboratory findings, secondary hyperglycemia was also suspected. Thyroid stimulating hormone level was normal $(0.618 \mu \mathrm{IU} / \mathrm{ml})$, but other hormone levels which can be associated with control of blood glucose levels were not measured (e.g. adrenocorticotropic hormone, cortisol, glucagon, or growth hormone). Based on the elevated alkaline phosphatase level and the elderly onset pattern of diabetes, we strongly suspected a pancreatic cancer in her differential diagnosis at first. Considering the low accuracy of conventional abdominal ultrasound study for diagnosing pancreatic tumors, we decided to perform the computed tomography instead of echography. Abdominal contrast-enhanced computed tomography detected the presence of a large necrotic mass on the inferior pole of the right kidney (see Figure 1). She was thereafter diagnosed with renal carcinoma. Her renal cancer was graded as stage II on account of a maximum tumor diameter of $67 \mathrm{~mm}$ (T1b) with no involvement of lymph nodes (N0) and no distant metastasis (M0) detected by chest and abdominal computed tomography.

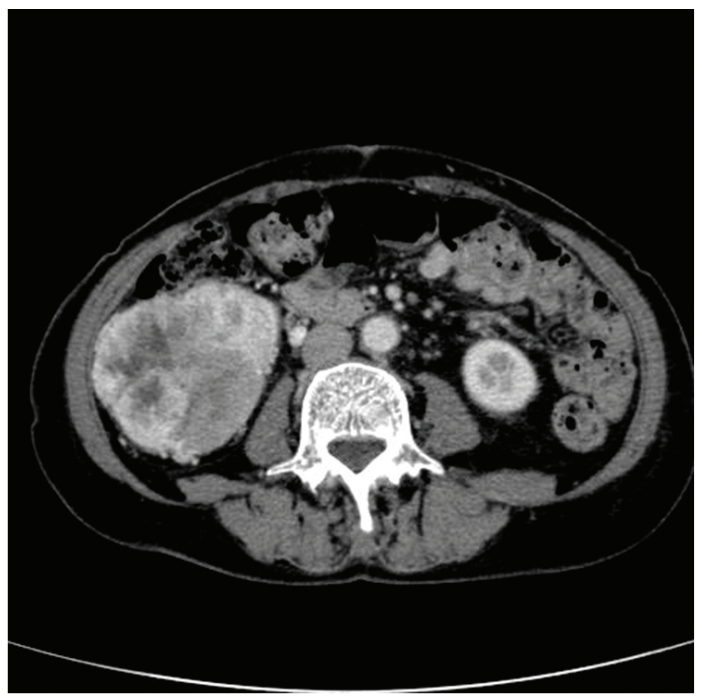

Figure 1. Abdominal contrast-enhanced computed tomography imaging (Axial image showing necrotic mass on the right kidney)

The patient was placed on a combination of insulin glargine and aspart. A total of 43 units of insulin per day were needed to maintain an acceptable blood glucose level in this patient. Her tachycardia subsequently returned to normal in parallel with the disappearance of ketonuria within several days of 
commencing insulin treatment; however, her transaminase and alkaline phosphatase levels became elevated, accompanied by decreased hemoglobin and albumin levels. She was then transferred to the urology department of another hospital for surgical management. One and a half months after admission to our hospital, her renal carcinoma was removed by laparoscopic nephrectomy. After surgery, her deranged laboratory readings (complete blood counts, hepatic enzyme levels, albumin levels, corrected calcium levels, and C-reactive protein levels) gradually returned to normal. In addition, insulin therapy was no longer required 2 months after surgery as a result of her improved glycemic control. At 1-year follow-up post initial admission, she was noted to be maintaining good hemoglobin A1c levels on $750 \mathrm{mg}$ of metformin daily (see Figure 2).

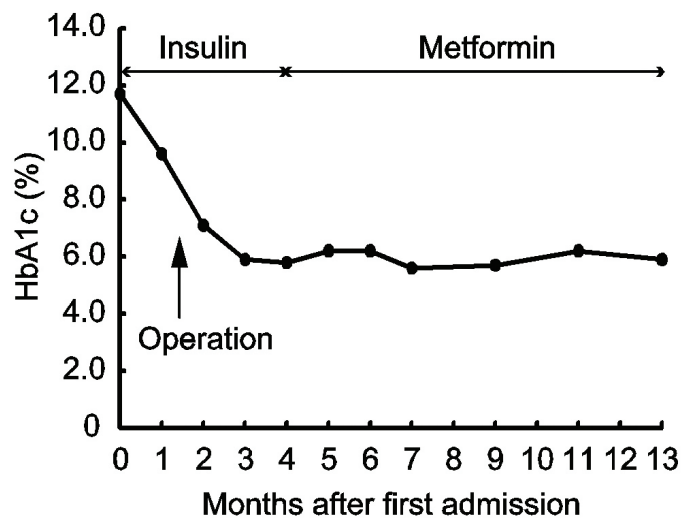

Figure 2. The course of glycated hemoglobin levels (Following surgical removal of the tumor, glycemic control improves, and insulin therapy is terminated)

\section{Discussion}

We report a case of renal cancer with new-onset hyperglycemia. Although hyperglycemia and renal cancer might occur independently of each other, based on the improvement in glycemic control following removal of the renal tumor, the patient's hyperglycemia could be assumed to most likely be associated with renal cancer. Although renal cancer was incidentally diagnosed, hyperglycemia and other abnormal laboratory findings, such as anemia and elevated levels of alkaline phosphatase and C-reactive protein, were keys to the diagnostic process in this case. This case therefore suggests that renal cancer should be considered in patients with newonset hyperglycemia and other abnormal laboratory findings, such as anemia or elevated levels of alkaline phosphatase or C-reactive protein, even in the absence of typical symptoms of renal cancer or microscopic hematuria.

New-onset or poorly-controlled hyperglycemia, thought to be associated with renal cancer, has been observed in a total of 11 cases including the present case. ${ }^{[2,3,6-12]}$ Patient characteristics in these cases are shown in Table 1. All patients were noted to be over 50 years old except in one case, 5 out of 11 cases involved new-onset hyperglycemia, and all cases were managed surgically. Before surgery, all cases had to either be commenced on insulin therapy or have their current insulin doses increased in order to control their serum glucose levels. Interestingly, glycemic control was improved in all cases, with 9 out of 11 patients no longer requiring insulin therapy following surgical removal of their tumors. Pathological investigation revealed no evidence of secretion of hormones, such as insulin, glucagon, somatostatin, or growth hormone. ${ }^{[7,9]}$

A differential diagnosis of renal cancer might seem farfetched based only on the presence of hyperglycemia in a patient. In fact, in four of the reported cases including this present case, renal cancer appeared to have been diagnosed incidentally by computed tomography in patients presenting with new-onset or poorly-controlled hyperglycemia without the presence of typical symptoms or urinary findings indicative of renal cancer, such as palpable renal masses, flank pain, and gross or microscopic hematuria. ${ }^{[3,9,11]}$ On the other hand, it is of note that in 3 of these 4 cases, patients exhibited abnormal hematology or serum biochemistry, including anemia and/or elevated levels of alkaline phosphatase and/or C-reactive protein. ${ }^{[3,11]}$ In addition, these abnormalities were also observed in other reported cases presenting with new-onset or poorly-controlled hyperglycemia, and eventually diagnosed with renal cancer. ${ }^{[2,6,8,10]}$ These clinical features, i.e., anemia, hepatic dysfunction, and prostaglandinelevation-related laboratory findings have been designated interleukin-6-associated paraneoplastic syndrome of renal cancer. ${ }^{[1,4,5]}$ With regard to hyperglycemia, although the precise pathophysiological mechanism remains unclear, the association between hyperglycemia and interleukin- 6 in renal cancer has also been suggested based on pathological findings from two previous case reports. ${ }^{[2,3]}$ On the basis of these findings, it might be suggested that hyperglycemia could frequently present with other interleukin-6-associated abnormalities in patients with renal cancer. Although further studies are needed to determine the exact association between hyperglycemia and interleukin-6 in patients with renal cancer, physicians should consider renal cancer as a differential diagnosis in patients with new-onset or poorly-controlled hyperglycemia occurring simultaneously with interleukin6-associated abnormalities such as anemia, deranged liver biochemistry, and elevated prostaglandin levels. 
Table 1. Patient characteristics of reported cases with simultaneously detected hyperglycemia and renal cancer

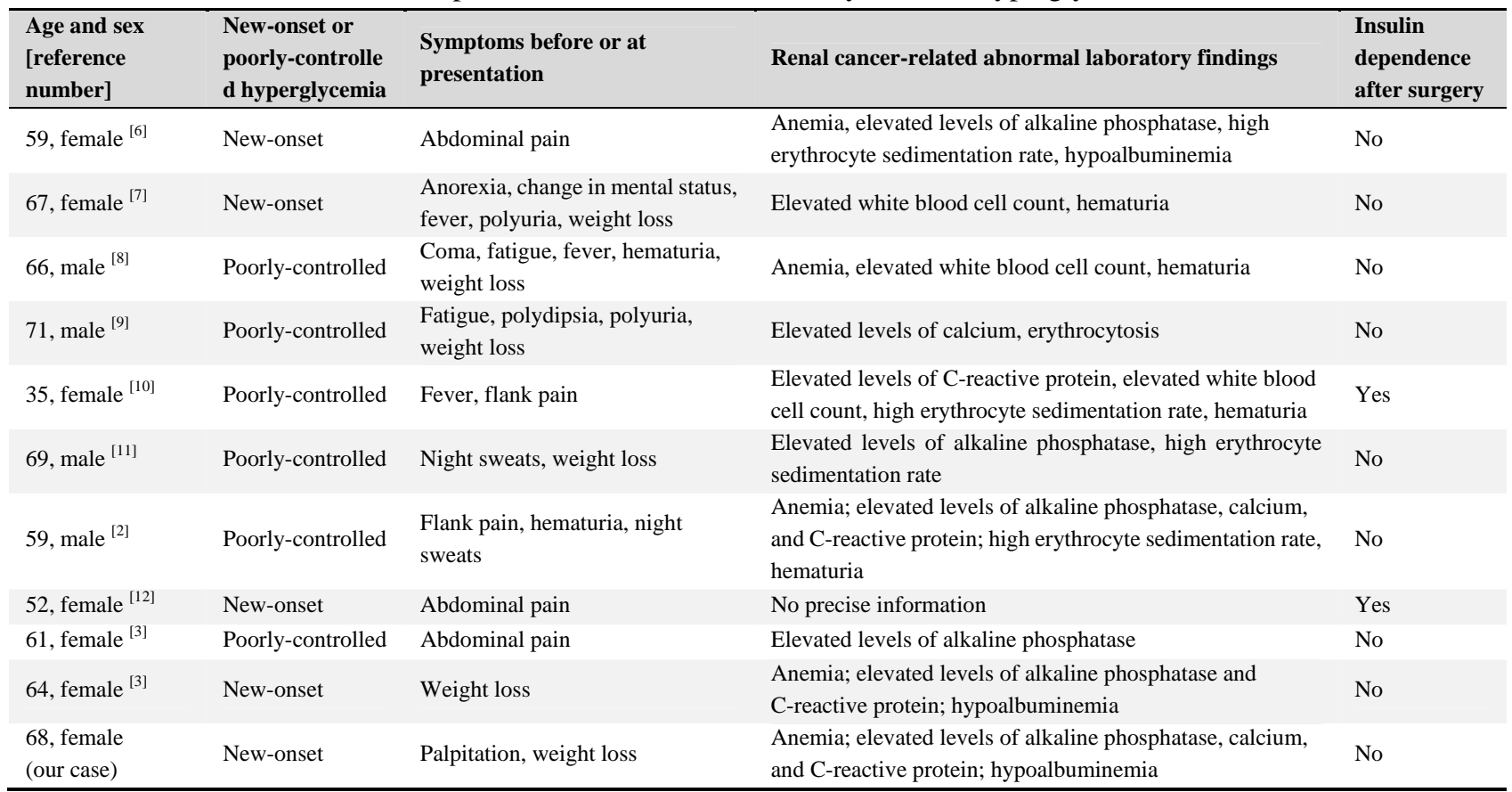

In conclusion, since new-onset or deteriorated hyperglycemia could present as a paraneoplastic syndromes of renal cancer in association with other interleukin-6-associated paraneoplastic syndromes, clinicians should suspect renal cancer in patients presenting simultaneously with these clinical features.

\section{CONFLicts OF INTEREST Disclosure} None

\section{REFERENCES}

[1] Palapattu GS, Kristo B, Rajfer J. Paraneoplastic syndromes in urologic malignancy: the many faces of renal cell carcinoma. Rev Urol. 2002; 4: 163-170. PMid:16985675

[2] Kazuhisa T, Yuji M, Masashi F, et al. [Hyperglycemia Associated with IL-6 Producing Renal Cell Carcinoma]. Journal of the Japan Diabetes Society. 2003; 46: 15-22. Japanese.

[3] Yumura Y, Yamashita Y, Senga Y, et al. [Two cases of renal cell carcinoma with diabetes mellitus that was healed after nephrectomy]. Hinyokika Kiyo. 2007; 53: 301-305. Japanese. PMid:17561714

[4] Falkensammer CE, Thurnher M, Leonhartsberger N, et al. Creactive protein is a strong predictor for anaemia in renal cell carcinoma: role of IL-6 in overall survival. BJU Int. 2011; 107: 18931898. PMid:21070572 http://dx . doi .org/10.1111/j.1464-4 10X.2010.09817.x

[5] Tsukamoto T, Kumamoto Y, Miyao N, et al. Interleukin-6 in renal cell carcinoma. J Urol. 1992; 148: 1778-1781. PMid:1433606

[6] Pavelić K, Popović M. Insulin and glucagon secretion by renal adenocarcinoma. Cancer. 1981; 48: 98-100. http://dx .doi.org/10.1002/1097-0142(19810701)48: 1<98: :AID-CNCR2820480119>3.0.CO;2-A
[7] Palgon N, Greenstein F, Novetsky AD, et al. Hyperglycemia associated with renal cell carcinoma. Urology. 1986; 28: 516-517. http: //dx .doi.org/10.1016/0090-4295 (86)90156-1

[8] Jobe BA, Bierman MH, Mezzacappa FJ. Hyperglycemia as a paraneoplastic endocrinopathy in renal cell carcinoma: a case report and review of the literature. Nebr Med J. 1993; 78: 349-351. PMid:8309485

[9] Matsumura T, Kihara K, Gotoh S, et al. [A case of renal cell carcinoma with hyperglycemia]. Nihon Hinyokika Gakkai Zasshi. 1996; 87: 1258-1260. Japanese. http://dx.doi.org/10.5980/jpnju rol1989.87.1258

[10] Callewaert PR, Van Poppel H, Vanderschueren D, et al. Uncontrollable diabetes mellitus: a rare paraneoplastic manifestation of renal cell carcinoma. Nephrol Dial Transplant. 1999; 14: 2263 2264. PMid:10489254 http://dx.doi.org/10.1093/ndt/14. 9.2263

[11] Macaulay CP, Pati JJ, Carr TW, et al. Renal cell carcinoma presenting with hyperglycaemia. BJU Int. 2002; 89: 789-790. PMid:11966650 http://dx.doi.org/10.1046/j.1464-410X .2002 .02687.x

[12] Elias AN. New-onset insulinopenic diabetes mellitus in a patient with an incidentally discovered renal cell carcinoma. Am J Med. 2005; 118: 1047-1048. PMid:16164894 http://dx.doi.org/10.1016 /j.amjmed.2005.03.009 